\title{
The influence of gravimetric moisture content on studded shoe-surface interactions in soccer
}

\author{
James Clarke $^{1} \cdot$ Matt J. Carré1
}

Published online: 11 October 2016

(c) The Author(s) 2016. This article is published with open access at Springerlink.com

\begin{abstract}
It is desirable for the studs of a soccer shoe to penetrate the sport surface and provide the player with sufficient traction when accelerating. Mechanical tests are often used to measure the traction of shoe-surface combinations. Mechanical testing offers a repeatable measure of shoe-surface traction, eliminating the inherent uncertainties that exist when human participant testing is employed, and are hence used to directly compare the performance of shoe-surface combinations. However, the influence specific surface characteristics has on traction is often overlooked. Examining the influence of surface characteristics on mechanical test results improves the understanding of the traction mechanisms at the shoesurface interface. This allows footwear developers to make informed decisions on the design of studded outsoles. The aim of this paper is to understand the effect gravimetric moisture content has on the tribological mechanisms at play during stud-surface interaction. This study investigates the relationships between: the gravimetric moisture content of a natural sand-based soccer surface; surface stiffness measured via a bespoke impact test device; and surface traction measured via a bespoke mechanical test device. Regression analysis revealed that surface stiffness decreases linearly with increased gravimetric moisture content $(p=0.04)$. Traction was found to initially increase and then decrease with gravimetric moisture content. It was observed that: a surface of low moisture content provides low stud penetration and therefore reduced traction; a
\end{abstract}

Matt J. Carré

m.j.carre@sheffield.ac.uk

1 Sports Engineering Research Group, Department of Mechanical Engineering, The University of Sheffield, Mappin Street, Sheffield S1 3JD, UK surface of high moisture content provides high stud penetration but also reduced traction due to a lubricating effect; and surfaces with moisture content in between the two extremes provide increased traction. In this study a standard commercially available stud was used and other studs may provide slightly different results. The results provide insight into the traction mechanisms at the stud-surface interface which are described in the paper. The variation between traction measurements shows the influence gravimetric moisture content will have on player performance. This highlights the requirement to understand surface conditions prior to making comparative shoe-surface traction studies and the importance of using a studded outsole that is appropriate to the surface condition during play.

Keywords Traction · Sport surfaces $\cdot$ Friction mechanisms $\cdot$ Football $\cdot$ Soccer $\cdot$ Moisture content

\section{Introduction}

Traction has long been cited as an extrinsic risk factor for lower extremity trauma injuries in soccer (caused by excessive loading) whilst being an essential requirement for athletic performance. Traction, in this article, is defined as the resistance to motion during studded shoe-surface contact. The tractional properties of a shoe-surface combination must therefore be within an optimal range [1]. Excessive rotational traction is related to injury risk whereas translational traction is related to performance as the player requires sufficient traction to accelerate from the surface. The relationship between traction, injury, and athletic performance has stimulated a great deal of recent research investigating shoe-surface interactions in sport, 
especially in soccer where studded shoes are used. Recent studies measure studded shoe-surface interactions via either biomechanical [3-10] or mechanical [11-22] techniques.

Biomechanical studies are vital to provide loading conditions and information that focuses on the key mechanisms and movements that effect traction and hence can give the boundary conditions for mechanical tests. Mechanical test devices have an advantage of creating objective loading conditions that provide a repeatable measure of shoe-surface traction, eliminating the inherent uncertainties that exist when human participant testing is employed. Mechanical test devices also provide an ethical method of testing under real-life loading conditions to provide an understanding of the physical interactions at play during shoe-surface interaction.

In 1986 Frederick [2] highlighted the requirement to develop repeatable mechanical test methods to quantify a range of traction that will allow acceptable athletic performance and injury risk. Therefore, numerous and varied mechanical test methodologies exist that measure traction at the shoe-surface interface in sporting situations [11]. Methodologies vary in terms of their loading conditions, driving mechanisms and the measurement of traction they extract [11, 12, 14-17, 20, 33]. These large variations and the differing surfaces and shoes tested make a direct comparison of results difficult and, despite some standard methodologies being defined for traction, there remains debate over how an acceptable range of traction can be determined and defined [11, 12, 14, 26]. Studies often neglect to provide insight into the traction mechanisms associated with the shoe-surface system of interest and the physical interaction between the studded outsole and the surface. There is, in general, a lack of quantified published research data relating specific surface properties and traction, particularly for natural sport surfaces [11,33].

Natural sport surfaces are complex surface systems comprising granular soil material (made up of sand, silt, and clay particles) and a grass plant [31, 32]. The tractional behaviour of a natural turf system has been found to be affected by a number of system and environmental variables-these are reported to include: particle make-up (termed 'mineralogy'); ground cover; grass species; grass root length and density; grass length; compaction; bulk density; temperature; and moisture content [23, 24, 28, 30-32]. Although advances in understanding the behaviour of natural turf systems have been made $[31,32]$, the high number of variables makes understanding the effects of an individual variable on player traction difficult. Orchard hypothesised a relationship model between surface traction, surface hardness, ground conditions and stud length which states that surface hardness and shoe-surface traction decrease with increasing soil moisture content [28]. This is in agreement with Canaway and Baker who concluded that moisture content is the dominant factor controlling surface hardness in natural sand-based soccer surfaces [23]. A link between the studies reviewed is the controlling effect moisture content has on soil strength and failure mechanisms. There remains, however, a gap in knowledge understanding how individual surface parameters, such as moisture content, affects the traction a studded soccer boot is likely to provide a player.

As opposed to comparing multiple shoe-surface combinations, the aim of this paper is to understand the effect that the moisture content of a natural turf system has on the tribological mechanisms at play during stud-surface interaction. Therefore, mechanical testing has been used in this work to provide an objective comparison between natural turf samples.

\section{Method}

Six samples of a natural soccer surface $(0.5 \times 0.5 \mathrm{~m})$ with a mixed sand, silt and clay make-up were removed from Norton Playing Fields, Sheffield, and brought into the laboratory. The samples were taken from the same area of the playing field to keep surface variables such as grass cover and length, root density, and soil particle make-up as consistent as possible. Soil analysis and mechanical tests (traction and impact) were carried out for each turf sample. The mechanical tests used an adidas World Cup stud, designed for the forefoot of the adidas World Cup soccer shoe (first released in 1954 and still popular at the time of writing). This is a metal stud and was chosen as a market leading typical stud designed for use on a natural surface (see Table 1). The tests conducted on each sample are described in detail below.

\subsection{Soil analysis}

\subsubsection{Gravimetric moisture content (\%)}

When evaluating standards for natural soccer pitch surfaces Baker found that the gravimetric moisture content in a mixed soil sand-based natural soccer surface varied between 15 and $45 \%$ throughout a soccer season in the UK [24]. Canaway and Baker commented that hardness fell below a preferred limit when the moisture content was within a range of 34-39\% [23]. Therefore, for this study it was assumed that a surface sample with gravimetric moisture content greater than $34 \%$ would be considered too soft, and hence unplayable. Before any mechanical testing the six samples were individually prepared to ensure they would all be in a condition considered playable 
Table 1 Dimensions of studs used in testing

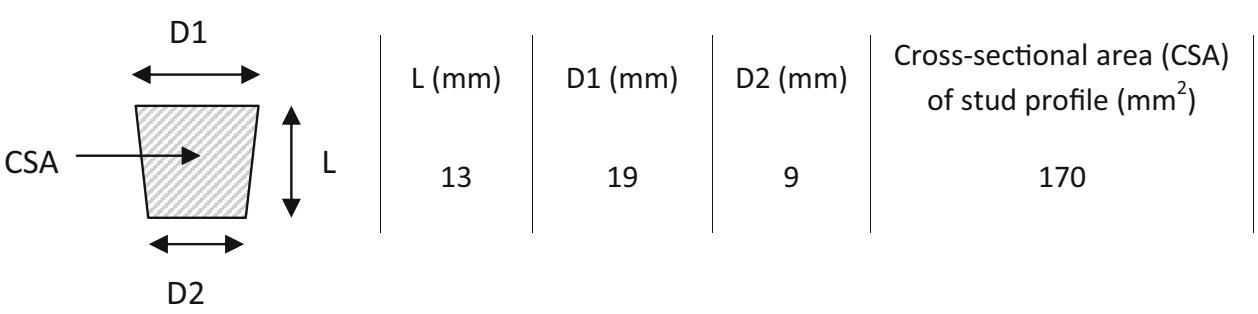

Table 2 Summary of gravimetric moisture content and bulk density of each sample

\begin{tabular}{|c|c|c|c|c|c|c|}
\hline \multirow[t]{2}{*}{ Sample reference } & \multicolumn{3}{|c|}{ Gravimetric moisture content (\%) } & \multicolumn{2}{|c|}{ Bulk density $\left(\mathrm{g} / \mathrm{m}^{3}\right)$} & \multirow[t]{2}{*}{ Preparation prior to mechanical testing } \\
\hline & Mean & St dev. & Significant differences & Mean & St dev. & \\
\hline A & 13.54 & 1.47 & $\mathrm{C}, \mathrm{D}, \mathrm{E}, \mathrm{F}$ & 1.16 & 0.08 & Oven-dried at $110^{\circ} \mathrm{C}$ for $4 \mathrm{~h}$ \\
\hline $\mathrm{B}$ & 15.23 & 5.83 & $\mathrm{D}, \mathrm{E}, \mathrm{F}$ & 1.21 & 0.07 & Oven-dried at $110^{\circ} \mathrm{C}$ for $2 \mathrm{~h}$ \\
\hline $\mathrm{C}$ & 17.41 & 4.41 & $\mathrm{~A}, \mathrm{D}, \mathrm{E}, \mathrm{F}$ & 1.23 & 0.15 & Allowed to dry indoors for $3 \mathrm{~h}$ \\
\hline $\mathrm{D}$ & 21.68 & 1.97 & $\mathrm{~A}, \mathrm{~B}, \mathrm{C}, \mathrm{F}$ & 1.26 & 0.05 & Kept outdoors and watered \\
\hline $\mathrm{E}$ & 23.03 & 2.59 & $\mathrm{~A}, \mathrm{~B}, \mathrm{C}, \mathrm{F}$ & 1.31 & 0.10 & Kept outdoors and watered \\
\hline $\mathrm{F}$ & 28.39 & 2.80 & $\mathrm{~A}, \mathrm{~B}, \mathrm{C}, \mathrm{D}, \mathrm{E}$ & 1.22 & 0.07 & Kept outdoors and watered \\
\hline
\end{tabular}

for soccer, but have varying gravimetric moisture contents (see Table 2).

Cylindrical soil cores with approximately $15 \mathrm{~mm}$ diameter and $50 \mathrm{~mm}$ length were taken from each turf sample to determine their gravimetric moisture content. Five cores were taken after the sample had been prepared but prior to any mechanical tests (which are described in Sect. 2.2), and five cores were taken immediately after the mechanical testing. Hence ten cores were taken in total per turf sample. Once taken, the mass of each core was immediately recorded. Each core was then oven-dried at $110^{\circ} \mathrm{C}$ for $24 \mathrm{~h}$ and the gravimetric moisture content was determined as the mean percentage weight loss of each core.

\subsubsection{Bulk density $\left(\mathrm{g} / \mathrm{m}^{3}\right)$}

Bulk density was determined as the ratio of the oven-dry mass of each cylindrical core and the volume occupied. Bulk density is regarded as a measure of soil compaction for soils with the same moisture content and/or soil composition. Increasing the bulk density increases the resistance to penetration which is related to the soil's stiffness and compressive strength [31, 32]. It can therefore be assumed that a surface considered to have a low bulk density will allow improved stud penetration, but reduced resistance to motion during stud-surface contact due to it having less material to overcome and move through.

\subsection{Mechanical tests}

\subsubsection{Normal impact tests}

The SERG drop hammer, a surface testing device developed by Carré et al. was developed to determine the normal impact characteristics of sport surfaces [25]. The SERG drop hammer (Fig. 1) is based on the Clegg impact hammer, which is commonly used to survey the hardness of sport surfaces [25].

For this study, the profile of the drop hammer was modified to include a stud as opposed to having the hemispherical profile described in Carré et al. this allowed an investigation into the penetration characteristics of studsurface combinations. The hammer contains an accelerometer and is dropped normally onto the surface. The device outputs a signal trace from the accelerometer throughout the entire time of an impact.

For this study the equipment had modifications to that discussed by Carré et al. the voltage signal from the accelerometer was sampled via a data acquisition device (National Instruments model number NI USB6008) in real time at $10,000 \mathrm{~Hz}$ and displayed in LabView (version 7.1 National Instruments). The result is a recorded output trace of signal voltage against time, throughout the loading and unloading phase of each impact (see Fig. 2). The unloading phase describes the contact between the hammer and the surface following the peak impact force. The signal was 


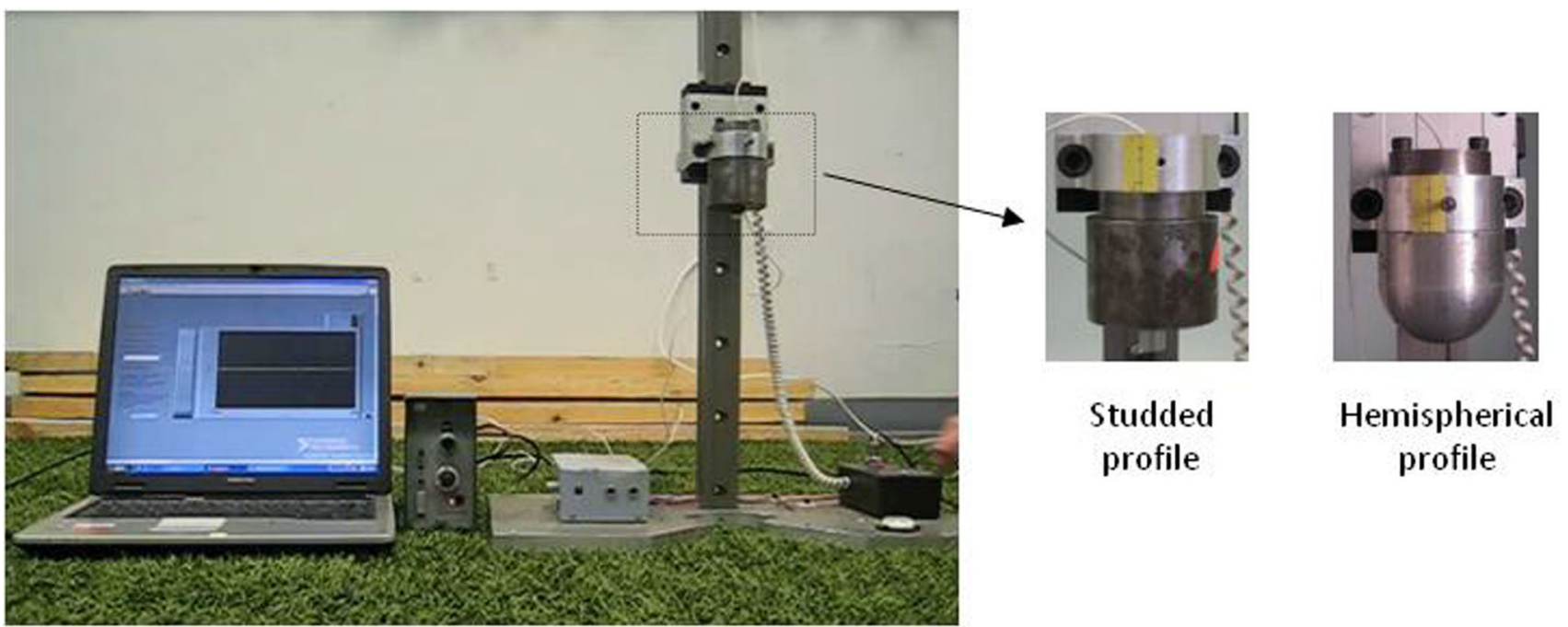

Fig. 1 SERG drop hammer setup and studded hammer profile and hemispherical hammer profile, modified from Carré et al. [25]. (Note: the studded profile presented here is not that used for testing-see Table 1)

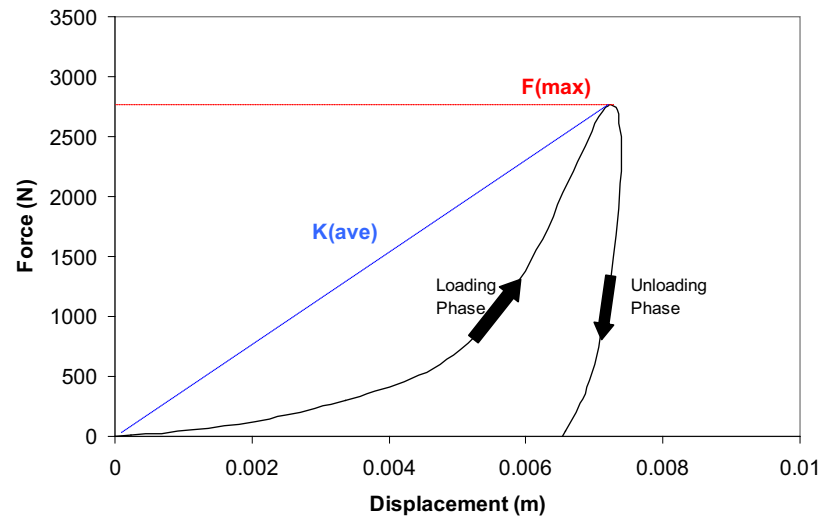

Fig. 2 Parameters recorded from a force-displacement curve to characterise the behaviour of the drop hammer-surface impact

sampled and transformed into force and displacement. From the raw trace data the acceleration during an impact can be found. Using the relationship $F=$ ma, a force displacement plot can then be formed. If the hammer is assumed to be rigid compared to the surface then it can be considered equivalent to a force deflection curve for the surface and can be related to surface stiffness.

Figure 2 shows a typical force displacement-curve (hysteresis loop) for an impact and highlights the parameters found for each trace in order to compare the characteristics of different surfaces. Plotting the hysteresis of an impact is a useful method to visually inspect and compare the normal impact characteristics of different surfaces. Parameters of interest from a hysteresis loop are as follows:

Peak impact force from loading The peak impact force $(F(\max ))$ is a measure of the maximum deceleration of the hammer during impact. Higher-impact decelerations suggest a surface is harder.
Average stiffness during loading phase This parameter $(K($ ave $)$ ) is the ratio of maximum penetration force over deflection of the surface at this point in time. It will relate to the resistance of penetration by the stud. By inspecting the loading phases of repeated impacts at different locations of a surface the mean average stiffness of the surfaces can be compared.

Ten repeated drops at the same drop height were performed on each sample. The peak impact force and average stiffness throughout the loading phase of each drop were determined. The results from these tests were used to understand the penetration characteristics of each turf sample. Regression analysis was used to determine the relationship between the drop hammer test results and the gravimetric moisture content results.

\subsubsection{Traction tests}

A bespoke mechanical traction testing device (Fig. 3) developed by Kirk was used to measure translational traction [26]. The test device measures the translational traction developed at the shoe-surface interface when a horizontal shear force is gradually increased. This is a valuable simulation as it provides a characteristic of the surface relative to the traction a player can experience- the force required to accelerate from a surface during a forefoot push-off before a slip occurs [26].

A hydraulic ram provides a controlled constant vertical load applied to a studded outsole. A high-pressure pneumatic ram provides a dynamic, increasing force in the horizontal direction. The horizontal load is controlled by a solenoid valve which is gradually opened to increase the force in the cylinder of the pneumatic ram. Load cells in the horizontal 

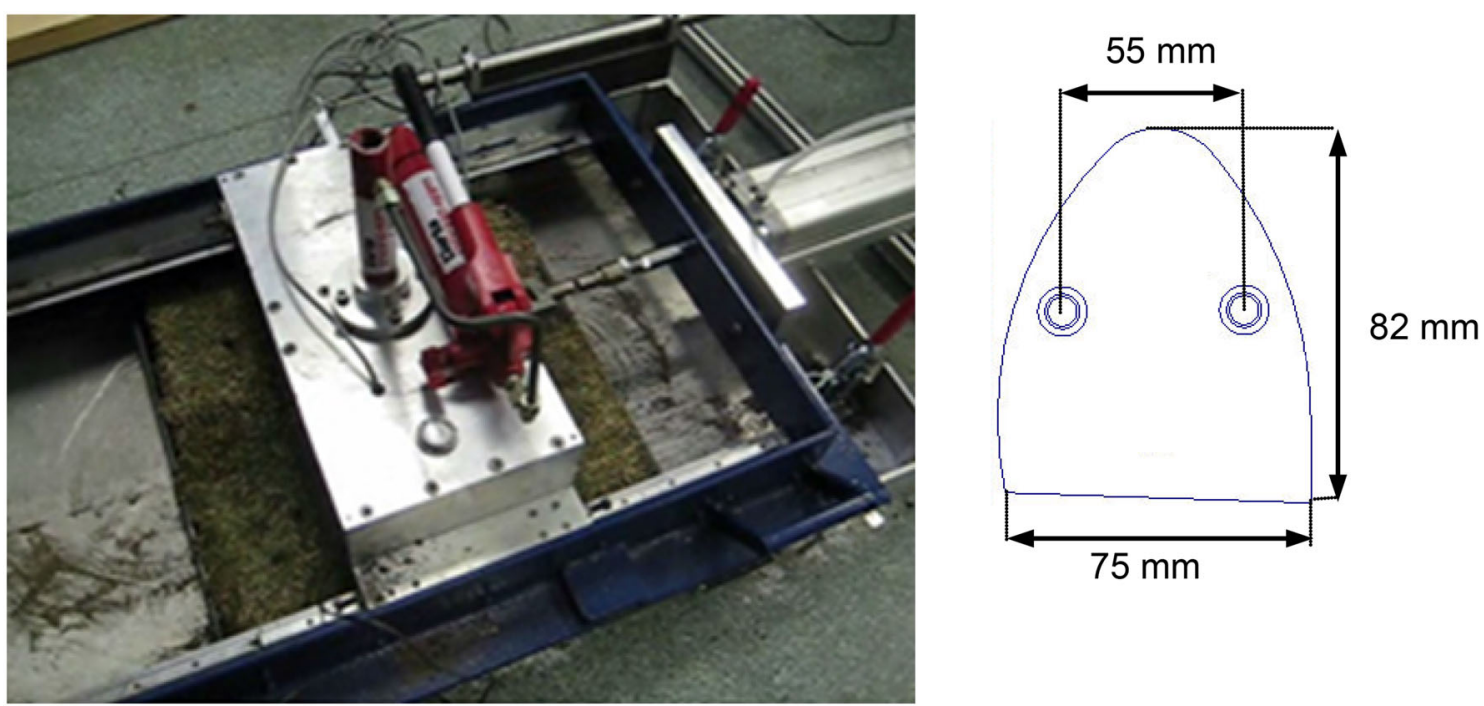

Fig. 3 Left: photograph taken during laboratory-based traction testing. Right: stud plate and configuration

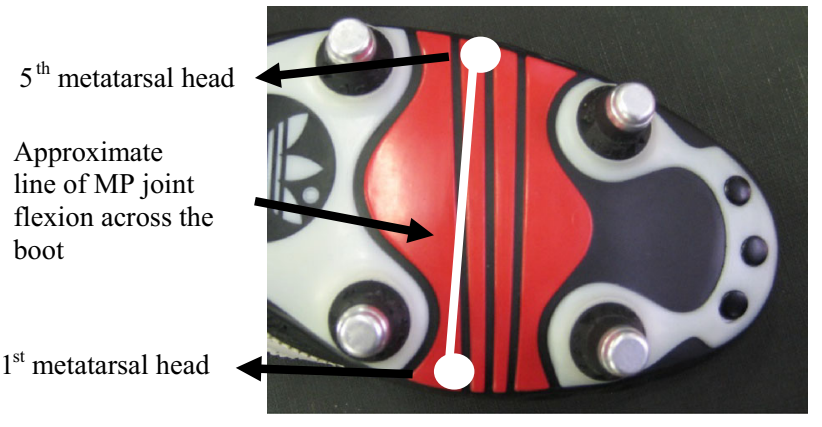

Fig. 4 The studded outsole of the forefoot segment on an adidas World Cup soccer boot, to show the studs in the forefoot segment which are likely to be in contact with the surface during forefoot push-off

direction and a Linear Variable Differential Transformer (LVDT) provide the necessary data to measure traction-the horizontal force resisting motion. Voltage signals from the load cells and LVDT are sampled simultaneously, via strain indicator boxes and a data acquisition device (National Instruments model number NI USB-6008), in real time and displayed in LabView (version 7.1 National Instruments). The signals are sampled and transformed into force and displacement measurements.

In this study, the traction rig was placed over a tray containing one of the natural turf samples and secured to prevent unwanted movement, shown in Fig. 3. This provided the device with rigidity and limited deviation in the applied normal force, a potential issue as reported by Severn et al. [11]. The tray containing the turf sample was also securely clamped into position.

The test device was developed to represent a soccer player performing a forefoot push-off, a movement which requires sufficiently high traction. The segment of a soccer boot outsole in front of the metatarsal-phalangeal (MP) joint is the only section in contact with the surface during the critical phase of a forefoot push-off [27]. Figure 4 shows that on the studded outsole of the adidas World Cup boot, the front two studs will therefore be in contact with the surface. During traction testing the studs were configured in this two-stud formation within a stud plate of the same dimensions, as shown in Fig. 3. The dimensions of the studs are shown in Table 1.

For each traction test a vertical force of $350 \mathrm{~N}$ was applied to the stud plate. This was found by Kirk to be representative of the vertical force (ground reaction) that occurs during the instant a player is at most at risk of slipping during a forefoot push-off [26]. The horizontal force after an initial displacement of $10 \mathrm{~mm}$ was used as a measure of traction. Kirk et al. showed that a surface 'gives' by approximately $10 \mathrm{~mm}$ during a movement when the player does not slip [27]. It can be argued that a horizontal displacement greater than $10 \mathrm{~mm}$ would result in the perception of a loss of traction (i.e. a slip). Traction tests were repeated five times at different location on each turf sample and the mean and standard error were determined.

\subsection{Statistical analysis}

PASW Statistics for Windows (Version 18.0 SPSS Inc. 2009) was used to perform statistical tests. One-way analysis of variance (ANOVA) tests were performed to determine statistically significant differences between two data sets. ANOVA tests assume normal (or Gaussian) distribution and produce a $p$ value (the probability data sets are significantly different) to assess the statistical significance between two data sets. In this study, it was decided that if $p<0.05$ then the data were significantly different. 
The square of the Pearson correlation coefficient was used to determine the strength of the linear correlation between data sets. As the coefficient tends to 1 the stronger the relationship is considered. The corresponding $p$ value (the probability that the relationship is significant) was used to determine if the linear relationship was statistically significant. In this study, if $p<0.05$ then a significant relationship between the two data sets is said to exist.

\section{Results}

Table 2 summarises the preparation procedures and also presents the mean moisture contents achieved (ranging between 13.5 and $28.4 \%$ ) and the bulk density test results after each sample was prepared. Figure 5 shows the moisture contents from the five cylindrical cores taken before testing and the five cylindrical cores taken after testing. The testing procedure lasted approximately $1 \mathrm{~h}$ and no significant differences were found between the gravimetric moisture content between the cylindrical cores taken before and after testing. Table 2 presents the significant differences between the gravimetric moisture content of the samples. It was assumed that the bulk density would be relatively constant as each sample was taken from the same section of the pitch. Although differences in the mean bulk density were found, ANOVA tests revealed no significant differences $(p=0.259)$ between the bulk density of any of the surface samples.

Representative force-displacement curves during the loading phase from the drop hammer tests are shown in Fig. 6. Surface A can be described as being a stiffer surface than surface F. Figures 7 and 8 plot the mean gravimetric moisture content $(\%)$ against the peak force $(\mathrm{N})$ and the mean average stiffness $(\mathrm{N} / \mathrm{m})$ (during the loading phase), respectively. The plots reveal how as the gravimetric moisture content decreases the peak force and the mean average stiffness increase.

Each traction test produced plots of horizontal force (i.e. traction) against horizontal displacement. Typical plots over $15 \mathrm{~mm}$ of displacement are shown in Fig. 9. Figure 10 presents a plot of mean horizontal force $(\mathrm{N})$ against mean gravimetric moisture content $(\%)$ for each of the six samples and are presented in three groups (1-3).

\section{Discussion}

\subsection{Discussion of normal impact test results}

Figures 7 and 8 show significant linear negative relationships between peak impact force and gravimetric moisture content $(p=0.006)$ and between average stiffness and gravimetric moisture content $(p=0.04)$, confirming an increase in penetrability with an increase in moisture content. This finding is in agreement with Canaway and Baker who found moisture content to be the dominant factor controlling surface hardness, and with Orchard, who concluded that natural surface hardness decreases as moisture content increases [23, 28].

Based on a study by Ayers and Perumpal, JenningsTemple extracted an idealised curve for the change in penetration resistance with increasing moisture content $[29,30]$. The curve shows how penetration resistance

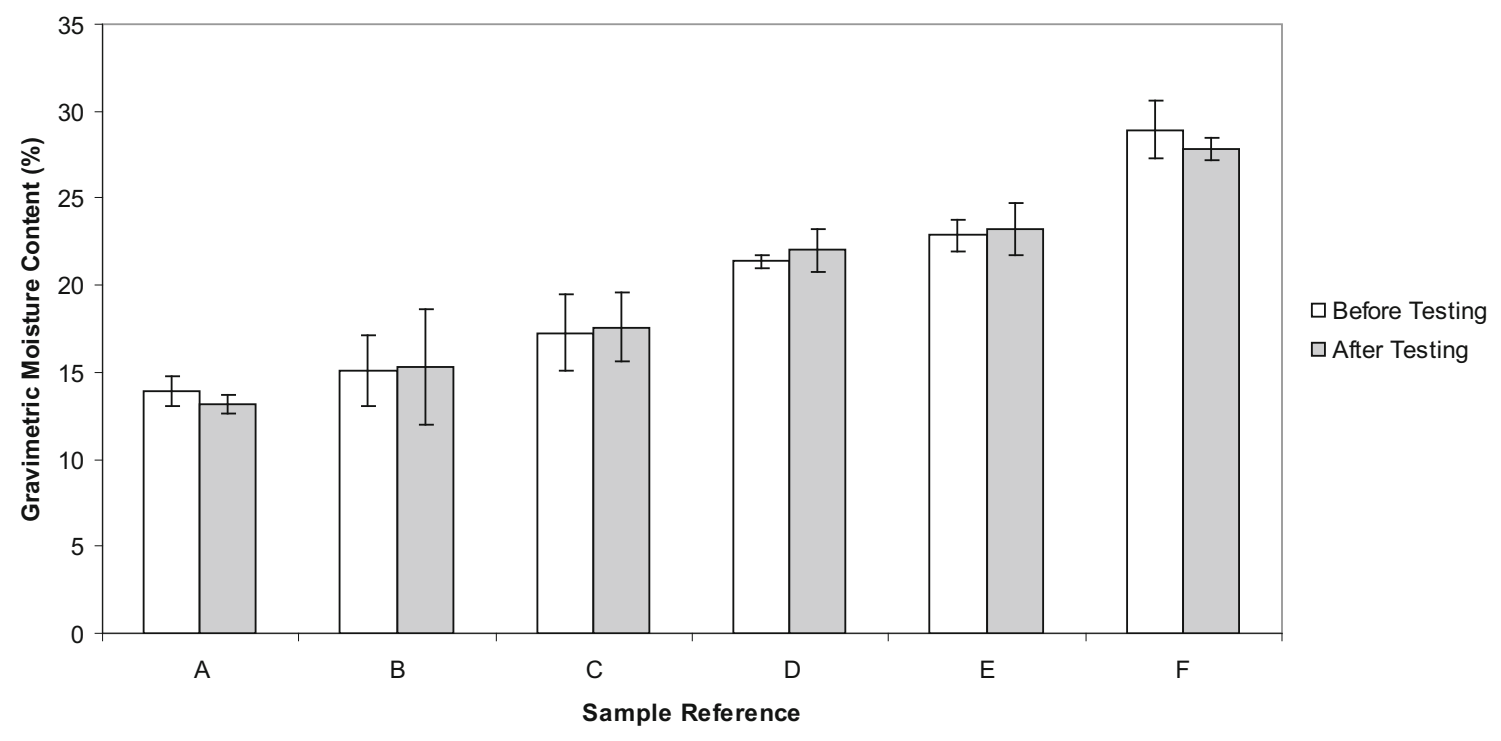

Fig. 5 Mean gravimetric moisture contents of the surface samples ( \pm 1 standard deviation) 
Fig. 6 Representative forcedisplacement plots from each surface sample during the impact phase of loading using the SERG drop hammer with studded profile

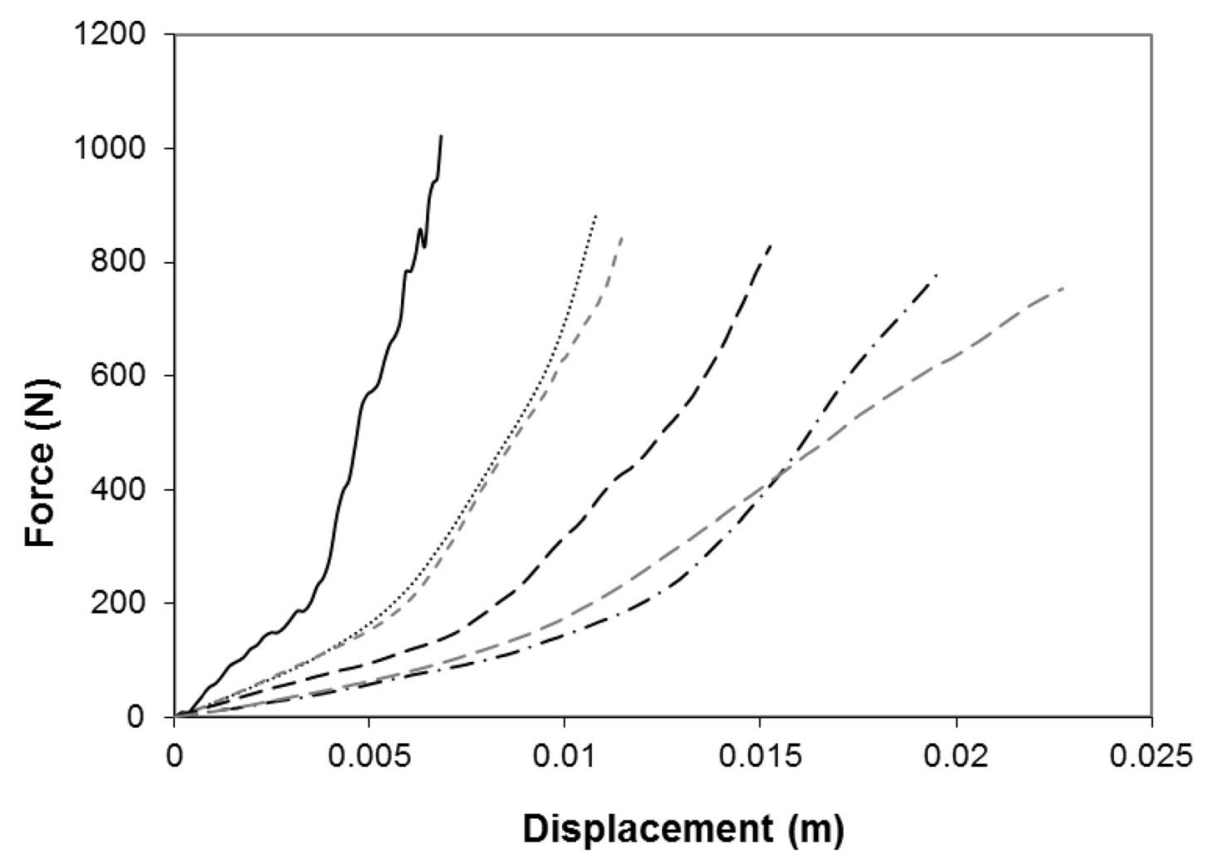

- Sample A

............. Sample B

- - - Sample C

-- Sample D

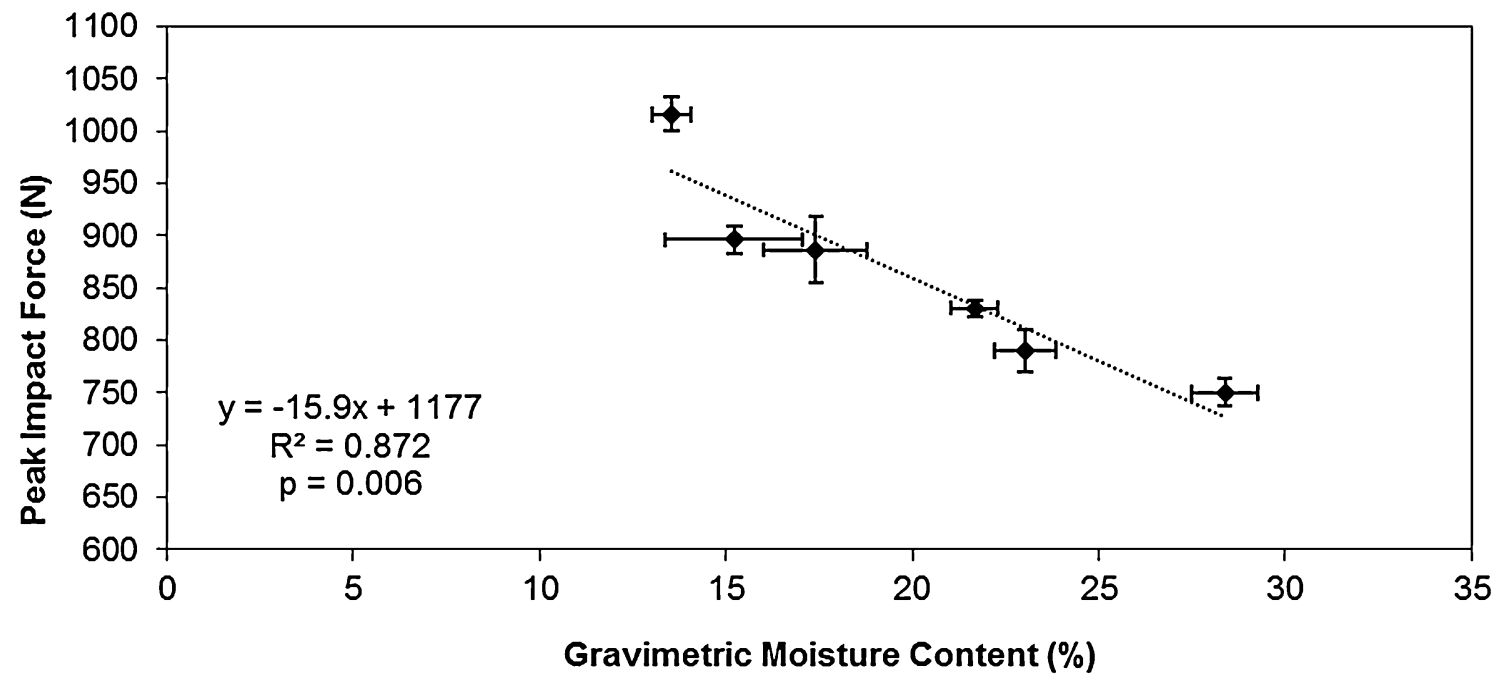

Fig. 7 Plot of mean peak impact force against mean gravimetric moisture content $( \pm 1$ standard error)

increases, peaks, and then decreases with increasing moisture content. In soils, low water content can increase the yield strength and the elastic moduli of the soil as films of water under tension pull particles together [26, 31, 32]. Guisasola et al. report that, at low water content, negative pore pressure causes cohesion from water films under tension at particle contact $[31,32]$. However, the addition of further water increases pore pressure reducing the cohesion between particles, and reducing the shear and yield strengths of the soil [26, 31, 32]. The addition of moisture also acts as a lubricant during stud-surface contact and at high moisture content the effects of bulk density can be ignored [31, 32]. The results from this study shows that the bonds that held the soil particles together have weakened with increased moisture content; also, that the moisture has acted as a lubricant reducing the friction force required for the soil particles to move past each other as the stud clears a path vertically into the surface. 


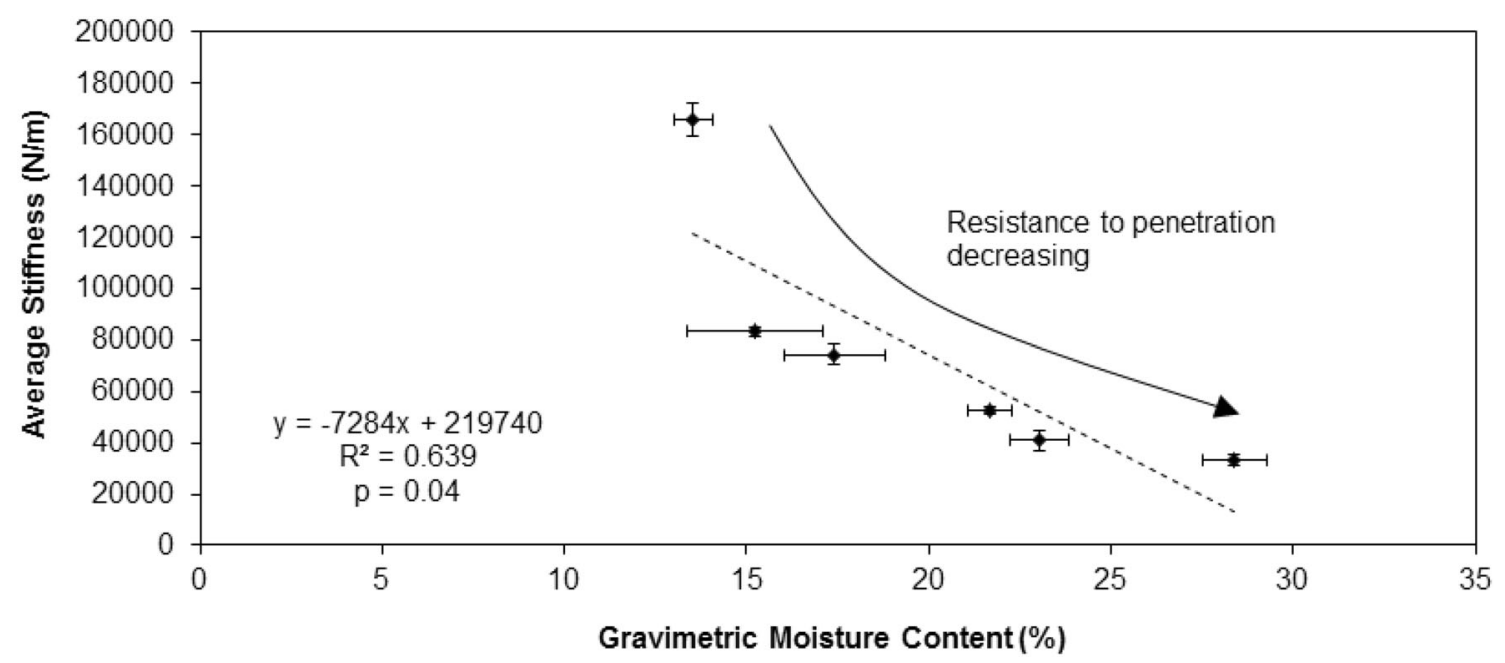

Fig. 8 Plot of mean average stiffness against mean gravimetric moisture content $( \pm 1$ standard error $)$

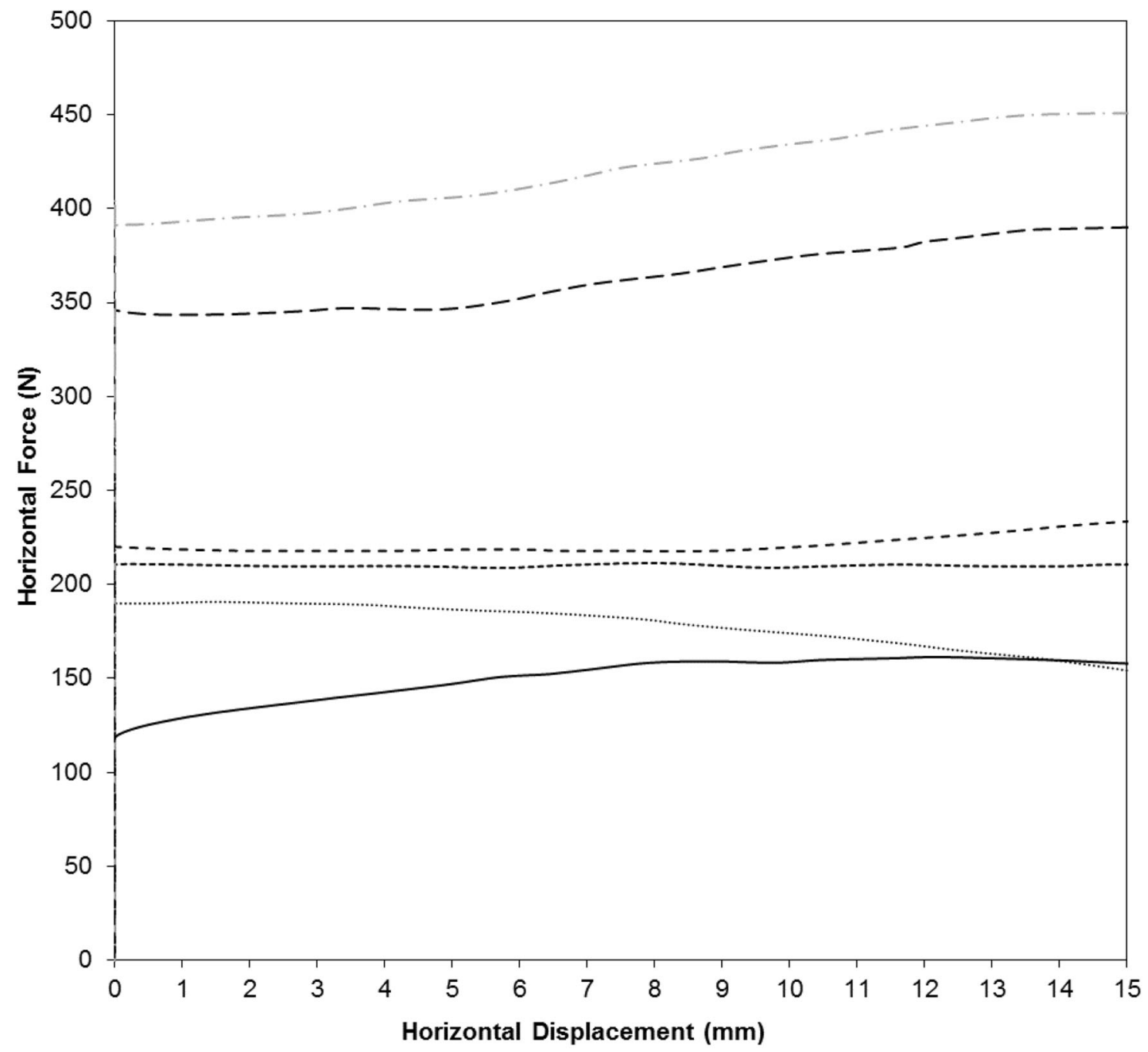

Sample A Sample B Sample C - - Sample D

Fig. 9 Representative plots of horizontal force against horizontal displacement for each surface sample using the traction testing device 


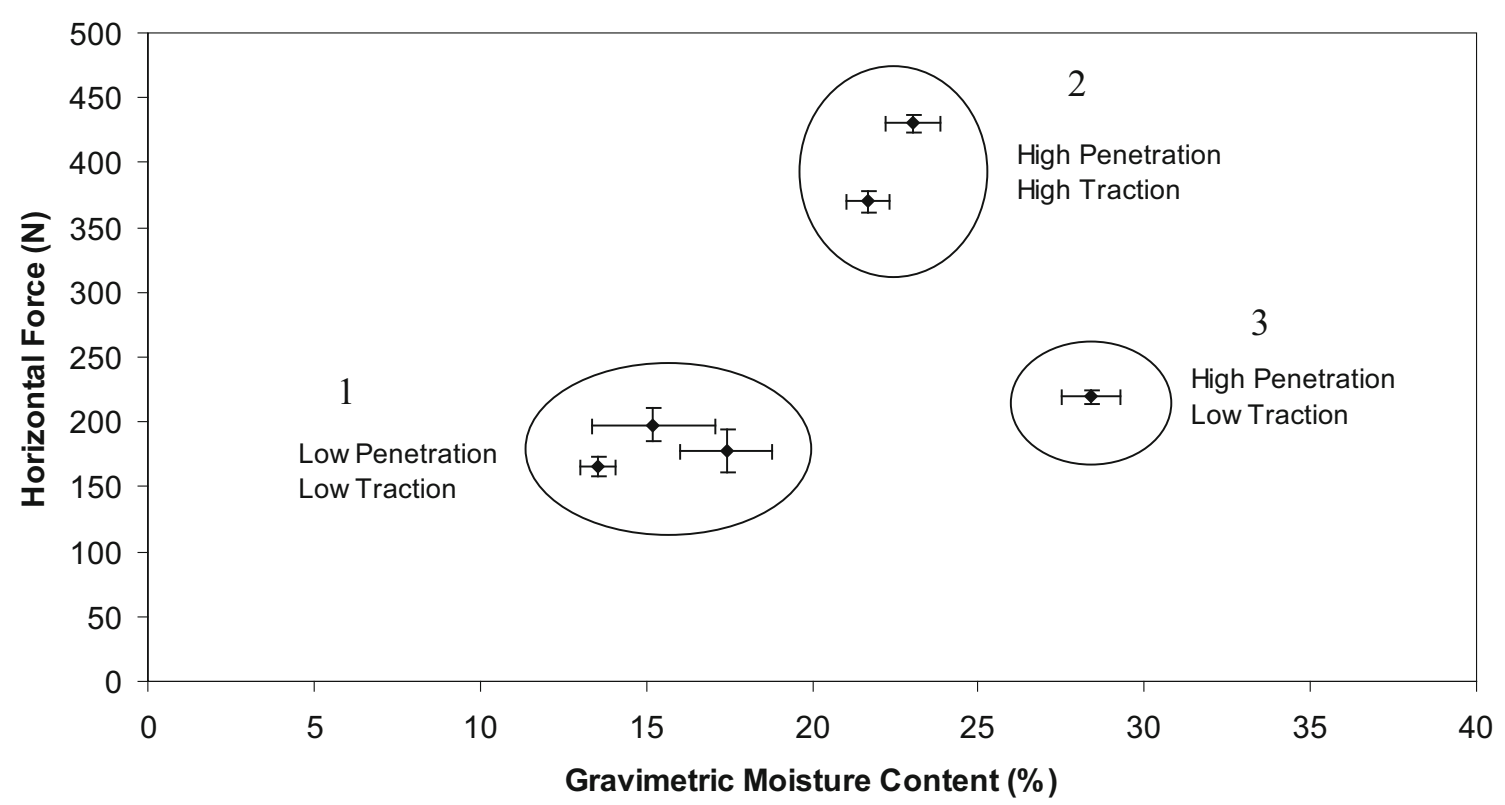

Fig. 10 Plot of mean horizontal traction force against corresponding mean gravimetric moisture content $( \pm 1$ standard error)

\subsection{Discussion of traction test results}

Figure 10 shows that the surface moisture content has a significant effect on traction. The surface with the highest moisture content (sample F) fails under a relatively low horizontal force, despite having higher stud penetrability. It was observed that full stud penetration was not possible on samples A, B and C during traction testing. The relatively low traction of these surfaces can be attributed to their poor penetrability. The samples (D and E) which offered the highest traction were the samples which had a soil strength that allowed a desirable balance between stud penetrability and resistance to horizontal force. This suggests that the adidas World Cup Stud is better suited to samples D and E as they will provide the player with the highest traction during a push-off. Future work should be done to fully substantiate this suggestion through further testing of surface samples.

The findings show how results from the traction rig could be misinterpreted. Although a result may show studsurface combinations to provide similar levels of traction (i.e. comparing groups 1 and 3), the penetration characteristics could be extremely different and this will influence a players comfort and stability [34]. This highlights the requirement to understand the influence of surface conditions when conducting investigations into shoe-surface traction.

In terms of the mechanical interactions that occur during testing, initially the traction rig quasi-statically loads the surface vertically via the hydraulic ram. Then the surface is horizontally loaded until surface failure occurs; in hard dry soils brittle shear failure occurs, while in softer soils shear failure occurs as a result of internal particle flow. The traction mechanism that describes how the surface fails for each of the groups of samples circled in Fig. 10 (1-3) are discussed in Sects. 4.3 and 4.4.

\subsection{Dry soil traction mechanism}

In group 1 (the samples with mean gravimetric moisture content from 13.5 to $17.4 \%$ ) it can be hypothesised that brittle failure occurs during vertical and horizontal loading. High resistance to penetration is due to high particle cohesion increasing resistance to compression and increasing its shear strength. This results in comparatively poor stud penetration as highlighted in Fig. 8. In stronger dry soils brittle failure occurs in the horizontal causing shearing along a slip plane. Particles above the slip plane are ruptured and displaced by the force driving the stud. This causes a build-up of surface material which may come into contact with the stud plate. This may result in an increase in traction as the movement develops and may explain why Orchard found peak traction recorded during a large movement increased with decreasing moisture content [28]. However, this study challenges this finding as only the initial movement of the stud is relevant to a soccer player, and it may be that this build-up has a negligible effect. Despite low moisture lubrication, and hence high inter-particle friction, the traction force is mainly affected by the low stud penetration, therefore the ploughing traction force and skin friction are relatively low and the plate friction is not contributing to the overall traction force. A 
This traction mechanism is dominated by: Cohesive shear strength in this region Inter particle friction in this region Shear strength in the horizontal plane

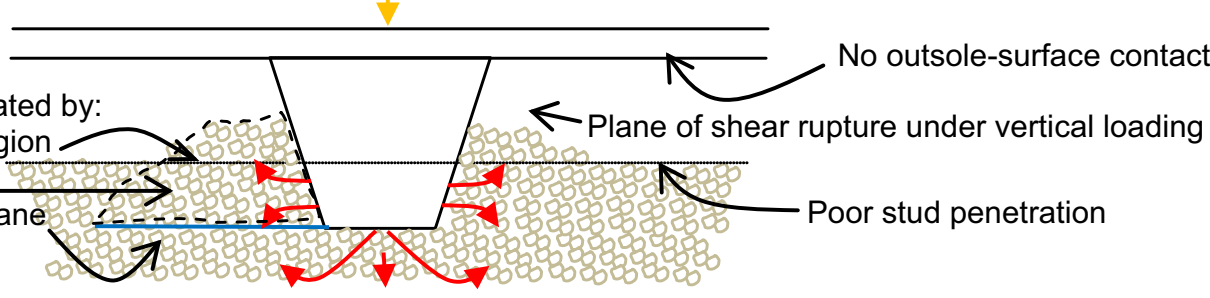

Surface displacement as surface shears under vertical loading

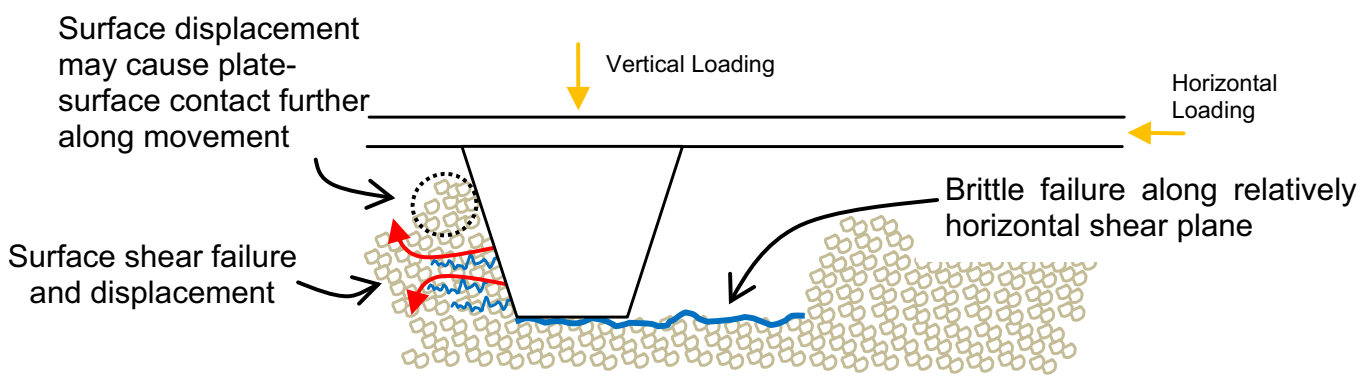

Fig. 11 The traction mechanism for surfaces with low moisture content (group 1). Top Surface failure under vertical loading. Bottom Surface after horizontal loading
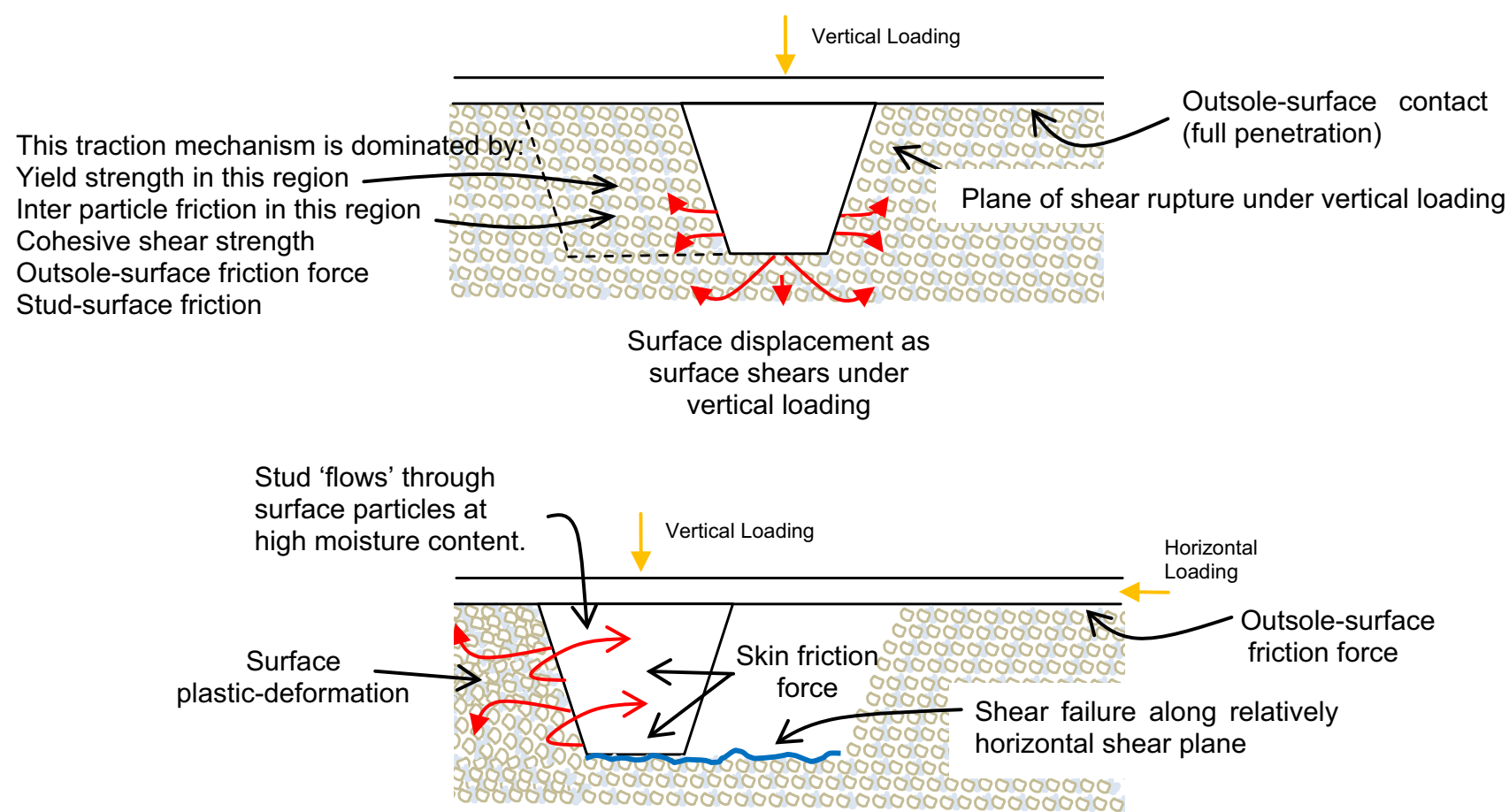

Fig. 12 The traction mechanism at higher moisture content (groups 2 and 3). Top Surface failure under vertical loading. Bottom Surface after horizontal loading

diagram explaining the traction mechanism is presented in Fig. 11. In this mechanism initially the traction is dominated by the soil particles resistance to shearing. As the stud moves the mechanism will also be dominated by the strength of the surface ahead of the stud, and the friction forces generated as surface materials interact. 


\subsection{Moist soil traction mechanism}

In soils a small addition of water can cause a transition from brittle failure to plastic flow failure [31, 32]. Therefore, in groups 2 and 3 (with mean gravimetric moisture contents from 21.7 to $28.4 \%$ ) surface failure may occur due to plastic yielding, as opposed to a brittle shearing. This failure mechanism is explained in Fig. 12. In group 2 the additional moisture content reduces particle cohesion and provides a lubricating effect which reduces inter-particle friction. The resistance to stud penetration via vertical loading is therefore lower than in group 1 (as shown in Fig. 10). As the stud vertically shears the soil during penetration, the pores of water will be broken and, via lubrication, reduce the skin friction forces and inter-particle friction forces resisting the stud from vertically clearing a path. In group 2 the high penetration characteristics will have contributed to the higher traction forces measured. Assuming the entire stud had penetrated the surface, a combination of the three contributing components of traction (ploughing traction force, skin friction, and plate friction) would explain the significantly higher traction forces measured in this group. In groups 2 and 3, assuming the moisture content had caused a transition to plastic flow failure, the traction mechanism is dominated by the interparticle friction as the stud clears a path through the surface; however, the skin friction and plate friction components will also contribute. It is possible that the relatively high bulk density value (although not significant) could have contributed to the traction measured.

The low traction force observed in group 3 will be due to the additional moisture content. The surface fails as a result of low resistance to particle flow; the high moisture content will result in poor particle cohesion and hence low soil shear strength. Despite having high penetration characteristics, when horizontally loaded, the inter-particle strength and stud-surface friction forces are significantly lowered by the lubricating effect of the moisture.

\section{Conclusions}

In soccer it is desirable for the studs of shoe outsole to penetrate the sport surface and provide the player with traction to push off from the surface.

An adidas World Cup soccer stud was attached to a drop hammer which was used to assess the penetrability of a natural turf surface at differing gravimetric moisture contents. Significant linear relationships were found to exist between the gravimetric moisture content with the peak impact force and the average stiffness from the impact phase of the drop hammer. As the gravimetric moisture content of a natural turf surface increases, the peak impact force and average stiffness decreases.

Mechanical traction tests were conducted to determine the influence the gravimetric moisture content of a natural turf surface has on the traction a soccer player might experience during play. Low gravimetric moisture content results in low stud penetration and hence low traction. High gravimetric moisture content results in high stud penetration but low traction, as the moisture acts as a lubricant. High traction is achieved when the moisture content of a surface is in between the two extremes, as the surface is sufficiently weak to allow stud penetration but sufficiently strong to provide horizontal resistance as the player pushes off.

It is dangerous to make conclusions on the performance (i.e. stud penetration and traction) of studded shoes based on a mechanical measure of traction alone. An understanding of the condition of the surface is required; this study shows that significant differences in gravimetric moisture content may not lead to significant differences in traction but will have an effect on stud penetrability and hence player performance.

Acknowledgments The authors would like to thank: the EPSRC for funding this work; adidas for supplying footwear; and the staff at Norton Playing Fields, Sheffield, for their help in providing surface samples.

Open Access This article is distributed under the terms of the Creative Commons Attribution 4.0 International License (http://crea tivecommons.org/licenses/by/4.0/), which permits unrestricted use, distribution, and reproduction in any medium, provided you give appropriate credit to the original author(s) and the source, provide a link to the Creative Commons license, and indicate if changes were made.

\section{References}

1. Milburn PD, Barry EB (1998) Shoe-surface interaction and the reduction of injury in rugby union. Sports Med 25(5):319-327

2. Frederick EC (1986) Kinematically mediated effects of sport shoe design: a review. J Sports Sci 4:169-184

3. Driscoll H, Kelley J et al (2014) Measurement of studded shoesurface interaction metrics during in situ performance analysis. Sports Eng 18(2):105-113

4. McGhie D, Ettema G (2013) On the 'trench effect' theory: a biomechanical analysis of the relationship between traction and shoe orientation on third-generation artificial turf. Footwear Sci $6(1): 41-50$

5. Brock E, Zhang S et al (2013) Effects of two football stud configurations on biomechanical characteristics of single-leg landing and cutting movements on infilled synthetic turf. Sports Biomech 13(4):62-79

6. Schrier NM, Wannop JW et al (2014) Shoe traction and surface compliance affect performance of soccer-related movements. Footwear Science 6(2):69-80

7. De Clercq D, Debuyck G et al (2014) Cutting performance wearing different studded soccer shoes on dry and wet artificial turf. Footwear Sci 6(2):81-87 
8. Sánchez-Sánchez J, García-Unanue J et al (2014) Influence of the mechanical properties of third-generation artificial turf systems on soccer players' physiological and physical performance and their perceptions. PLoS One 9(10):e111368

9. O'Connor A-M, James IT (2013) Association of lower limb injury with boot cleat design and playing surface in elite soccer. Foot Ankle Clin 18(2):369-380

10. Iacovelli JN et al (2013) The effect of field condition and shoe type on lower extremity injuries in American Football. Br J Sports Med 47(12):789-793

11. Severn KA, et al (2010) Science of synthetic turf surfaces: a comparison of traction test methods, in Science, Technology and Research into Sport Surfaces, Loughborough

12. Twomey DM, Connell M, Petrass LA (2014) Rotational traction testing: how can we improve the current test device? Proced Eng 72:919-924

13. Twomey DM et al (2013) The effect of stud configuration on rotational traction using the studded boot apparatus. Sports Eng $16: 21-27$

14. Twomey D et al (2011) Reliability of equipment for measuring the ground hardness and traction. Proc Inst Mech Eng Part P 225:131-137

15. Webb C, Forrester S, Fleming P (2014) Rotational traction behaviour of artificial turf. Proced Eng 72:853-858

16. Kent $\mathrm{R}$ et al (2012) Development and assessment of a device and method for studying the mechanical interactions between shoes and playing surfaces in situ at loads and rates generated by elite athletes. Sports Biomech 11(3):414-429

17. Wannop JW, Luo G, Stefanyshyn DJ (2012) Footwear traction at different areas on artificial and natural grass fields. Sports Eng 15(2):111-116

18. Robindronath D, James D (2014) The effect of stud shape on penetration characteristics through synthesized natural turf in football. Proced Eng 72:648-653

19. Moez SB et al (2014) Rotational and peak torque stiffness of rugby shoes. Foot 24(3):107-110

20. Kent R et al (2012) Development and assessment of a device and method for studying the mechanical interactions between shoes and playing surfaces in situ at loads and rates generated by elite athletes. Sports Biomech 11(3):414-429
21. Serensits TJ, McNitt AS (2014) Comparison of rotational traction of athletic footwear on varying playing surfaces using different normal loads applied. Turfgrass Sci. doi:10.2134/ATS-20130073-RS

22. Fabio Galbusera F et al (2013) Does soccer cleat design influence the rotational interaction with the playing surface? Sports Biomech 12(3):293-301

23. Canaway P, Baker S (1993) Soil and turf properties governing playing quality. Int Turfgrass Soc Res J7:192-200

24. Baker SW (1989) Soil physical conditions of the root zone layer and the performance of winter games' pitches. Soil Use Manag 5(3): $116-122$

25. Carré MJ et al (2006) Hybrid methods for assessing the performance of sports surfaces during ball impact. Proc Ins Mech Eng Part L 220:31-39

26. Kirk RF (2008) Traction of association football boots. PhD. Thesis, The University of Sheffield

27. Kirk RF et al (2007) High-speed observations of football boot surface interactions of players in their natural environment. Sports Eng 10(3):129-144

28. Orchard J (2001) The AFL penetrometer study: work in progress. J Sci Med Sport 4(2):220-232

29. Ayers PD, Perumpral JV (1982) Moisture and density on cone index. Trans ASAE 25:1169-1172

30. Jennings-Temple M (2005) Linking soil moisture status of winter sports pitches to measures of playing quality. EngD. Thesis, Cranfield University

31. Guisasola I, James I et al (2009) Quasi-static mechanical behaviour of soils used for natural turf sports surfaces and stud force prediction. Sports Eng 12(2):99-109

32. Guisasola I, James I et al (2009) Dynamic behaviour of soils used for natural turf sports surfaces. Sports Eng 12(3):111-122

33. Clarke JD (2011) Understanding the performance and comfort of soccer boots. PhD. Thesis, The University of Sheffield

34. Clarke JD, et al (2010) A player-perception study of the comfort of soccer boots. The impact of technology on sport 3. Honolulu, Hawaii, USA, 21 September 2010-23 September 2010, pp 201-205 